\title{
1. Crashing down from a blue sky: the political management of COVID-19 in New Zealand
}

Nigel Haworth

Everybody knows that pestilences have a way of recurring in the world; yet somehow we find it hard to believe in ones that crash down on our heads from a blue sky. There have been as many plagues as wars in history; yet always plagues and wars take people equally by surprise. Albert Camus, The Plague

\section{INTRODUCTION}

In December 2019, a mysterious pneumonia-like outbreak was reported in Wuhan, People's Republic of China. By the time New Zealand re-elected a new government in October 2020, the world was facing a global second wave of COVID-19. Since its appearance, more than 50 million cases have been identified internationally. New Zealand has weathered both first and second waves, having just overcome a second small wave of community transmission and, overall, experiencing a modest 1886 cases and 25 deaths. This brief analysis offers, first, a heuristic model against which to compare the New Zealand approach to the pandemic; second, a brief explanation of national political governance in New Zealand; third, the rationale of the government's response to COVID-19, with some commentary on related matters; fourth, some conclusions about short- and long-term consequences of COVID-19 for political governance in New Zealand.

\section{A FRAMEWORK FOR THE ASSESSMENT OF PRACTICE}

Janssen and van der Voort (2020) provide a helpful framework for the subsequent discussion. In particular, the 'adaptive governance' model (Bronen and Chapin, 2013) is consistent with the key features of New Zealand's management of the COVID-19 crisis. Here, I am particularly interested in Janssen and 
van der Voort's (2020) 'lessons for practice' derived from their study of the Dutch management of COVID-19. They conclude:

- There is no 'one best response' and, indeed, there is great value in having available a variety of response strategies. Thus, national responses, as in the case of New Zealand, will tend to the eclectic, contingent and location specific;

- Responses will change over time. The mix and intensity of government interventions will vary as the pandemic flows and ebbs;

- Adaptation (change) in the mix and intensity of responses is best accompanied by stability, that is, effective change is supported by populations continuing to enjoy a sense of stability in society;

- Government must mobilize society in support of its pandemic strategy. People must feel confident and respected in the implementation of interventions. Hence, communication is important as is its perceived authenticity. Equally, I suggest, the nature and quality of national leadership is important in societal mobilization.

Subsequent discussion will show that these lessons for practice conform closely to the New Zealand experience, particularly in terms of, first, contingency in response planning driven by the scale of the crisis and, second, the importance of community support for government actions.

\section{NATIONAL POLITICAL GOVERNANCE IN NEW ZEALAND}

New Zealand's three-year electoral cycle is short, with two modalities. An established government, re-elected, usually comes to power with one or more cycles of governance in hand, and is able to build on existing personnel and legislative initiatives. The second modality arises when a government takes office after a significant period in opposition. In 2017, the Labour-led government took power somewhat unexpectedly, after nine years in opposition, with few seasoned senior politicians and an unwieldy dependence on three political parties, two of which (Greens and New Zealand First) were not happy bedfellows.

Labour was last in government in 2008, contributing to its relative inexperience in 2017, and owed much of its success in the 2017 election to a strong popular response to Jacinda Ardern, who ascended to party leadership a matter of weeks before the election. New Zealand First offered one of the most experienced (and iconoclastic) politicians in New Zealand in Winston Peters. The Greens were inexperienced in government and grappling with strong internal 
currents around political focus - environment versus radical social change and willingness to make the compromises necessary in government.

In this second modality, inexperience, combined with a somewhat unexpected rise to power, resulted in an inevitable period of adjustment to power as, for example, freshly minted ministers grappled with the mechanisms of authority. Simultaneously, the breadth of the governing coalition had a constraining effect on policy implementation as policy differences intruded.

Against this background of constrained policy implementation, the 'rhythm' of government provided an overlay. That rhythm is in general bi-modal. Government is a skein of activities, some focused on policy and its implementation, and others on day-to-day political management. In the first mode, government is bound by established rules and norms, both formal and informal, laid down by the Speaker, Parliamentary Service, party whips, political party constitutional requirements, security requirements, to name but some. In general, much of this is understood and managed with little significant disruption.

The second mode - rarer and of a different order - is illustrated primarily by the impact of global economic disruption, war or similar 'shocks' which lie unquestionably outside the usual expectation of government. Post 2017, the Labour-led government has faced one other crisis approaching this order of events - the terrorist attack in Christchurch in 2019. Arguably, however, despite the appalling nature of that attack, the COVID-19 challenge is substantially greater in impact, akin to that of the Great Depression, and, perhaps, the Second World War. The defining characteristic of this mode is a level of disruption such that orthodox government management practices are insufficient to manage the scope and scale of events. When COVID-19 struck, neither politicians nor officials had first-hand experience of a shock of this order and did not possess a 'play book' to consult.

The COVID-19 pandemic drove a disrupted order. COVID-19 plunged national governance into an unheralded and comprehensive challenge to political management. As we see below, the New Zealand government was fortunate to grasp the implications of the crisis relatively early and configured itself institutionally and strategically equally early. It followed an adaptive governance model of response to a disrupted order.

\section{DEVELOPING THE RATIONALE: GO HARD, GO EARLY}

The essence of the New Zealand government strategy was to 'go hard, go early', combining a strong social cohesion focus with complementary legal backing. This has proved to be a successful approach, with New Zealand implementing an early and strict lockdown, ahead of much of the OECD, 
coupling that urgency with, for example, a broad and simple wage subsidy for both employees and the self-employed, full-time and part-time, which rapidly supported over 1.6 million people in the workforce.

\subsection{Why 'Go Hard, Go Early'?}

The structural advantage of New Zealand's political model is immediately apparent. The unicameral arrangement with effective national oversight unimpeded by powerful state or provincial political arrangements permitted a strong centralized unitary response. Authority to act rested unequivocally in central government.

The tradition of a Cabinet-led government, itself led by the Prime Minister, created a ready-made crisis management executive, in principle able to oversee a whole-of-government approach to the pandemic. In practice, this model was rapidly refined during the practice of crisis management. In practice, the Prime Minister and Minister of Finance formed a very tight core group, immediately supported by two other senior ministers with specific COVID-19-related charges. Other ministers were brought into the mix as needed, but a core political executive, supported by core government officials and other extra-official advisers, emerged as a crisis management executive.

Executive control of this order has both management and political $/$ messaging dimensions. Paramount in government thinking was the need to lead New Zealand through this crisis at minimum human cost. However, it was also a political challenge, in which a general election in October 2020 loomed large. However intense a crisis may be, a weather eye on electoral prospects will also inform policy implementation and messaging.

\subsubsection{Using and managing technical expertise}

Another factor in the executive management mix is the role of technical expertise. The government has access to advice from ministries and their officials, but, equally, in highly technical matters such as the pandemic, it calls on specialist knowledge, especially from medical experts. Such expertise is not bound by the disciplines attached to civil service status, and is also deeply centred in a broader professional world in which political considerations take second place to professional standards. In turn, external technical voices have in general been measured and supportive of government action, creating an environment in which public technical disagreement has been rare and in which both sides have been responsive. In the New Zealand context, personal networks have played an important role in this accommodation.

Managing technical inputs and commentary also raises the issue of data management. This had two major dimensions. The first was to involve the public in data generation, especially by means of the NZ COVID-19 Tracer 
app (the mobile phone app distributed to allow people to track their whereabouts). The second was to manage the public dissemination of data about cases and government initiatives. The flagship event in this was the daily briefing in which the status of the Prime Minister was coupled with that of the Director-General of Health. Those briefings were something of a masterclass in the public presentation of often technical and complex, and usually politically sensitive, data. Their aim was simultaneously informative - for example, how many new cases; educative - for example, wash your hands frequently; and political - generally, we have this crisis in hand, our strategy is working, the 'team of 5 million' will vanquish the threat.

\subsubsection{Government intelligence sources}

The government acted in response to a wide variety of information flows along multiple channels. Notably, there were four particular sources, which, together, informed both understanding of the crisis and the need for early, rapid and effective action. The first source derived from close commercial ties with China. A fall-off in trade early in the crisis led to, for example, lay-offs in the New Zealand logging industry, in part driven by the COVID-19 outbreak in China. The government became aware early of this dislocation. Second, the networks linking the Chinese diaspora were very quick to signal the gravity of the Wuhan outbreak. Private commercial and political networks were rapidly appraised of these concerns by New Zealand's Chinese community. Third, there is a corps of New Zealand specialists involved with trade and business matters linking New Zealand and China, some resident in China, others in New Zealand, who also signalled the scale of the crisis in China. They networked with ministers and officials, emerging as important sources of data analysis of events and consequences. Fourth, the government's own political antennae - official and unofficial - were receiving confirmatory messages about the Chinese situation.

\subsubsection{The challenge of 'whole of government response'}

The scale of the crisis required a whole-of government response, which in turn required the imposition of overall political control of decision making. The advantages of whole-of-government decision making in New Zealand government have been considered for at least two decades, but its practice is impeded in part by the institutional impact of leadership and culture in ministries, and in part by the political sensitivities of ministers. It often becomes simply too hard to achieve, despite valiant efforts. The New Zealand government managed this challenge by imposing strong, central political leadership. By lodging strategy determination and consequent decision making in a small group of ministers, it overcame substantially the potential for inter-agency differences, whilst also 
creating a strong central performance appraisal mechanism overseeing agency performance.

\subsubsection{The nature of leadership}

The emergence of a tight leadership cadre within the government was not a fortuitous coincidence, but the conscious building on an established political order within government. The Prime Minister sat at the apex of the response, unassailed in any way by internal political challenges, and able to counter challenges from the political opposition. As the 2020 election results have shown, the political reach of the Prime Minister is commanding. The political victory in 2017, the response to the Christchurch attack and the White Island volcanic eruption, the international focus on her premiership, all came together to empower her leadership. It is clear that her standing resulted in challenges to the government's management of the crisis being more easily explained and banished.

Even before the crisis, the government's leadership mode tended towards attenuation, that is, a clear distinction between the Parliamentary Caucus and Cabinet-level ministers, and a further distinction in influence between ministers. Indeed, all prime ministers have an 'inner group' of ministers and advisers with greater access to information and impact on decisions. That attenuation was increased during the crisis by the need to integrate political decisions with technical advice on a day-to-day, sometimes hour-to-hour basis. In the event, primary political leadership settled in a group of four ministers in which two had primacy. The rationale for this lay in performance factors - for example, ministerial performance, skillsets and judgement - and personal factors - for example, long-established trust relationships. Labour as a party is not factionalized, so there is little, if any, factional pressure on such roles. Where a prime minister commands support as does the incumbent, her writ is strong.

\subsection{The Rationale for the Government's Approach to COVID-19}

Early in the COVID-19 crisis, the government determined to build on high levels of social cohesion within New Zealand as the foundation for action. The notion of the 'team of 5 million' came to reflect this approach. A key dimension of the team was social cohesion - the skein of beliefs, norms and practice which allowed New Zealand to operate broadly around the pandemic on a unitary basis. Central to this was trust and its legacy built up through the Christchurch and White Island events, embodied in the person of the Prime Minister. She was the lynchpin of the unitary response, the 'necessary but not sufficient' condition for successful management of the crisis.

The government understood early the need to gain mass support for its strategy so the role of the Prime Minister was complemented by a powerful 
communications strategy emphasizing a unitary approach grounded in a vision of 'kindness'. Confidence in the technical advice used by the government was built round regular communication with increasingly respected commentators, especially the Director-General of Health and a core group of epidemiologists and other medical experts. The economic support packages introduced were similarly understood to be a response on behalf of the team. Benefit increases and compassionate responses to the homeless reflected unitary social interventions.

The government also understood that, whilst voluntary compliance was always preferable, there would be a need to discipline some citizens into compliance. Here, again, the 'team' traditionally displays a strong commitment to the 'rule of law', an advantage that would support the need for compulsion in some circumstances. Thus, the government consciously sought the 'sweet spot' between voluntarism and compulsion, emphasizing the former but unequivocal in its willingness to use the latter if necessary. Clearly, this was a matter for constant assessment and management, and inevitably an unremitting concern - achieving the optimum balance was the goal, with an understanding that failure to do so would result in greater levels of compulsion, and the probable loss of social commitment to the government's COVID-19 strategy. The spectre of events in, for example, the USA and the UK loomed large in this concern.

\subsection{Legislative Management}

The scale of COVID-19's challenge raised legislative and constitutional challenges. At a simple functional level, Parliament found its essential functions disrupted by COVID-19 measures. One response by government was to establish a Select Committee of Parliament, chaired by the Leader of the Opposition, to meet virtually during lockdown, between 25 March and 26 May. The purpose of the committee was to consider and report to the House on matters relating to the government's management of the COVID-19 epidemic. This committee had a two-fold function - to give practical meaning to parliamentary oversight of the handling of the crisis and to confirm for civil society that the democratic process still functioned. The nomination of the Leader of the Opposition as chair of the committee was politically astute.

In August 2020, a panel of three High Court judges issued findings in relation to a claim raised by Anthony Borrowdale to the effect that, first, the initial nine days of lockdown were illegal; second, three Orders made by the Director-General of Health relating to social gatherings and other matters exceeded the powers permitted under the relevant parts of the Health Act 1956; third, the Director-General had unlawfully delegated the definition of 'essential services' used in COVID-19 management to the Ministry of 
Business Innovation and Employment. The High Court found fault only in the first matter, and, even then, it stated: 'While there is no question that the requirement was a necessary, reasonable and proportionate response to the COVID-19 crisis at that time, the requirement was not prescribed by law and was therefore contrary to s 5 of the New Zealand Bill of Rights Act' (Borrowdale v Director-General of Health [2020] NZHC 2090 [292]).

In May 2020, the COVID-19 Public Health Response Act was passed, illustrating the government's requirement for urgent legislative management of the crisis. The need for special legislation to deal with Level 2-type lockdowns is interesting. On the one hand, it shows that the Health Act 1956 in general continues to be an effective measure for dealing with many of the circumstances that arise in a pandemic. On the other, the need for specific legislation to permit previously unlegislated degrees of lockdown, and the willingness of opposition parties in Parliament to oppose such legislation, captures the emerging politicization of the anti-COVID-19 campaign as a general election approached and as the merits of the 'Go fast, go hard' approach were subjected to political scrutiny.

\subsection{Managing Key Interest Groups: Business, Labour}

Business sentiment throughout the crisis has been guardedly positive. Criticism has arisen in relation to, for example, the timing and configuration of government support for business, the perceived limited role of senior business people in developing the COVID response, and the impact of stringent lockdowns on business activity. However, the scope and size of government financial support for business as the pandemic developed was such as to mute criticism. That support was generous and easy to access. As BusinessNZ (2020) said in relation to the 2020 General Election:

This year's [election] survey shows a clear view by business that the Government has done well in its initial response to the COVID-19 situation. There are mixed feelings about whether the Government has spent the right amount on business support, but there is strong support for the wage subsidy and leave schemes. (para. 3)

BusinessNZ is making a distinction also made by the New Zealand Council of Trade Unions (CTU). This is between the immediate response to the pandemic's dislocation and longer-term recovery initiatives. The CTU has been equally positive about the government's short-term measures but also sees the need (especially post-2020 General Election) for the much-heralded legislation of Fair Pay Agreements and further reform of the employment relation legislation, coupled to industry planning. 
In sum, in terms of the social partners - unions and employers - relations with the government have been active and substantive. Ministers have gone some way to ensure that communication channels are open and receptive. However, both social partners are now focused on the post-COVID-19 recovery phase, which promises to be a more challenging engagement around the configuration of recovery.

\subsection{Managing the Media}

Messaging has been central to the government's COVID-19 strategy. The government, and particularly the Prime Minister and Minister of Finance, have a complement of internal and external advisers, press secretaries and strategists supporting press-government relations. Contacts with the media exist on and off the record. From the government's side, management of relations with the media is, in general, effective. From the media perspective, shortened news cycles, reductions in resources and funding and the emergence of new social media platforms produce a richer texture of both informed and uninformed comment, and a move away from in-depth extended analysis.

Against this background, the government has shared news management between the four core ministers, the Director-General of Health and a small number of officials. Media engagement has been tightly managed. The focus of the government's media strategy has been fourfold - to inform the public of developments on a daily basis, impart important behavioural messages, promote the unitary national strategy and publicly anchor decisions in technical advice, rather than political requirements. This approach has been sustained and successful.

\section{IT'S THE ECONOMY, STUPID: BUDGETS AND COSTS}

Government economic management of the crisis is an important measure of popular, media and expert commentary. This is inevitably a highly charged political matter, which came to figure large in the 2020 General Election. Traditionally, management of the economy is an area in which, rightly or wrongly, the National Party eclipses Labour in polls. Hence, the government laid great stress on both its generosity (that is, the extent and size of expenditure), the success of the expenditure (that is, the jobs and firms supported) and its grasp of the consequences of such expenditure (that is, how debt consequent on expenditure would be managed). This was, clearly, a delicate and crucial balancing act. To give perspective, by April 2020, the government had committed $\$ 41.9$ billion to the COVID-19 response, with $\$ 20.2$ billion in hand for further allocation. Net core Crown debt was 19 per cent of gross domestic 
product year ending June 2019; it is projected to rise to 53.6 per cent in years ending June 2023 and 2024. Notwithstanding these challenging figures, one can sum up a generally positive business commentary in a quote from $\mathrm{PwC}$ New Zealand's (2020) budget commentary: 'This is a big, bold Budget. The government has sent a strong signal that they are committed to economic recovery from COVID-19, and are ready to keep spending to speed up the recovery' (para. 1).

A Newshub-Reid Research poll published in July 2020 suggested that, given the question of which party would run New Zealand's economy better through the COVID-19 crisis, 62.3 per cent of respondents said Labour and 26.5 per cent National (Lynch, 2020). In support of this, Grant Robertson (Minister of Finance) was chosen by the NZ Herald's 'Mood of the Boardroom' CEOs as the top-performing Cabinet Minister (O’Sullivan, 2020).

\section{INTERNATIONAL DIMENSIONS}

At the time of writing (December 2019), the World Trade Organization (2020) is forecasting a 9.2 per cent drop in world merchandise trade in 2020, followed by a 7.2 per cent increase in 2021 . These data are more tentative than is usually the case, but certainly more positive than some earlier forecasts of COVID-19's impacts on global trade. Some New Zealand trading sectors have been hard hit, especially education and tourism. Other sectors have been significantly less disrupted. In New Zealand, the government reacted to this trade challenge with a Trade Recovery Strategy (Parker, 2020). The core components of this are direct support to exporters, a focus on a reformed international trade regime and an upgrading of key international trade links. The emphasis lies in a trading system that rebuilds quickly and better as a result of COVID-19.

Migration issues are also important, in particular in relation to regular and anticipated movements of labour into New Zealand. Such movements - be they seasonal agricultural workers from the Pacific Region, fishing crews from the Caucasus or international performers for New Zealand-based film productions - carry with them risks of reintroduction of COVID-19 (as was seen in the case of some migrant fishers, who, upon arriving in New Zealand to crew New Zealand-based fishing vessels, in some cases tested positive for COVID-19). The government has carefully monitored this demand for access, recognizing economic imperatives but refusing to subordinate medical advice to economic considerations.

Geo-politically, COVID-19 has thrown up myriad challenges. For example, how may travel between China and New Zealand be managed when the Chinese claim the defeat of COVID-19? What should be the status of travel between New Zealand and Australia? Or New Zealand and the Pacific Islands? 
Suffice it to say that in both international economic and diplomatic terms, COVID-19 has been severely disruptive.

\section{CONCLUSIONS AND DISCUSSION}

\subsection{Reflecting on Janssen and van der Voort}

The relevance of the Janssen and van de Voort (2020) discussion of 'lessons for practice' should be clear. New Zealand neither chose nor developed a 'one best response'. The scale of the pandemic drove something akin to a 'just-in-time' response to the crisis, contingent on particular circumstances as they emerged in New Zealand. The success of a just-in-time approach was made possible by a number of factors - for example, the capacity to drive a unified national response, the quality of science-based advice, the commitment of the population to an effective response and the quality of national political leadership.

The just-in-time element of the response was also a source of flexibility in, and nuancing of, intervention. Whilst flexibility did lead on occasion to uncertainty in policy delivery, in general it allowed national leadership to adjust policy in a timely fashion.

A hallmark of the New Zealand experience was the dialectic between changing policy responses to COVID-19 and stability in messaging and policy delivery. Stability was enshrined in the use of a handful of 'talking heads' in the media, messaging around the unity of the ' 5 million' and the persona of the Prime Minister and her carefully crafted and consistent presence. The government positively counterposed the unity and coherence of society to the pandemic-related uncertainties.

The mobilization of the ' 5 million' against COVID-19 built on the impact of the earlier Christchurch terrorist attack. The New Zealand population has displayed to date high levels of discipline and adherence to pandemic-related regulations. There is a chicken-and-egg dimension to this - early discipline proved effective and permitted later freedoms barely constrained domestically by regulation.

\subsection{Thinking Ahead}

For the New Zealand government, COVID-19 promises an uncertain future. Government sources are sanguine about COVID-19 vaccine development and anticipate its availability in early 2021, with substantial supplies flowing in mid-2021. Much depends on that outcome. The government remains hopeful that the social cohesion displayed since the pandemic arrived will continue to support effective counter-COVID-19 measures. Furthermore, there is hope 
amongst government economists (and others) that the economic recovery from COVID-19 will be ' $v$-shaped'.

Budget 2020 in large part rested on these assumptions. Key themes of the Budget - jobs, training and infrastructure - were predicated on not just maintaining workforces and skills for a rapid recovery, but also on using the disruption of the crisis as an impetus to improved economic performance. The business community and many economic commentators are sympathetic to this approach. Interestingly, the more radical suggestions emerging are from the government's own supporters, such as an interest in modern monetary theory.

Let us assume that a vaccine is available from mid-2021, a reasonable assumption given news of vaccine development success in early November 2020. At some point thereafter, government performance will be subject to a post-COVID-19 reckoning. As Camus writes, plagues and wars do seem to take people by surprise, but they are also rapidly consigned to history as the immediate takes precedence over the past. The government will have only so long in which it can blame COVID-19 for its challenges.

Domestically, the government will be expected to have managed a variety of matters well. Unemployment is one; growth rates and their impact on inequality and investment will be another. The question will be asked: has the trading system recovered sufficiently to support the needs of a strong trade-based economy? Will financial support through the crisis have contributed to the transformation of the economy to a high-performance model? To what extent will COVID-19 have 'crowded out' essential economic changes driven by climate change, or will the government have grasped the opportunity to rebuild with climate at the centre of its policy thinking? Is there social partnership, which is committed jointly to a transformed New Zealand? Such questions are many, but they point to the opportunity to change New Zealand for the better - the silver lining of the crisis to be acknowledged and seized. Hence, all eyes are on a government with an extraordinary mandate after the 2020 General Election. To what extent will it be transformational?

Internationally, the government has the potential to play a major role in re-energizing the international trade system and contributing to global diplomatic arrangements that rebuild, rather than fragment. New Zealand has been a powerful voice, far more effective than its economic presence might suggest, in international councils on trade and diplomatic collaboration. One obvious context in which New Zealand counsels are heard is Asia-Pacific Economic Cooperation (APEC), which China and the US are also members of. An economic rapprochement between China and the US in a post-Trump world would be an important building block for the post-COVID-19 international economy. 


\section{REFERENCES}

Borrowdale v Director-General of Health [2020] NZHC 2090.

Bronen, R. and F. Chapin (2013, June 4), 'Adaptive governance and institutional strategies for climate-induced community relocations in Alaska', PNAS, 110 (23), 9320-25. https://doi.org/10.1073/pnas.1210508110

BusinessNZ (2020), 'Business Covid and the 2020 election', accessed 27 Nov 2020 at https://www.businessnz.org.nz/news-and-media/media-releases/2020/business, -COVID,-and-the-2020-election

Janssen, M. and H. van de Voort (2020), 'Agile and adaptive governance in crisis response: Lessons from the COVID-19 pandemic', International Journal of Information Management, 55, 102180.

Lynch, J. (2020), 'Newshub-Reid Research poll: Kiwis trust Labour more than National to run the economy', Newshub, 27 July, accessed 27 Nov 2020 at https:// www.newshub.co.nz/home/politics/2020/07/newshub-reid-research-poll-kiwis-trust -labour-more-than-national-to-run-the-economy.html

O'Sullivan, F. (2020), 'Mood of the boardroom: Grant Robertson impresses the business leaders', NZHerald, 28 September, accessed 27 Nov 2020, at https://www .nzherald.co.nz/business/mood-of-the-boardroom-grant-robertson-impresses-the -business-leaders/T2FSWAHSHDY74F5723BELTI3AA/

Parker, D. (2020), 'Trade strategy for the recovery from the impacts of Covid-19', 8 June, accessed 27 Nov 2020, at https://www.beehive.govt.nz/speech/trade-strategy -recovery-impacts-COVID-19

PwC New Zealand (2020), 'Budget 2020', accessed 27 Nov 2020, at https://www.pwc .co.nz/insights-and-publications/budget/nz-budget-2020.html

World Trade Organization (2020), 'Trade shows signs of rebound from COVID-19, recovery still uncertain', accessed 27 Nov 2020, at https://www.wto.org/english/ news_e/pres20_e/pr862_e.htm 